\title{
Withania somnifera extract reduces the invasiveness of MDA-MB-231 breast cancer and inhibits cytokines associated with metastasis
}

\author{
Kamel F. Khazal', Donald L. Hill ${ }^{2}$ \\ ${ }^{I}$ Department of Biomedical Sciences, School of Veterinary Medicine, Tuskegee University, Tuskegee, Alabama 36088, USA. \\ ${ }^{2}$ Division of Preventive Medicine, University of Alabama at Birmingham, Birmingham, Alabama 35294, USA.
}

Correspondence to: Dr. Kamel F. Khazal, Department of Biomedical Sciences, School of Veterinary Medicine, Tuskegee University, Tuskegee,

Alabama 36088, USA. E-mail: kamel@mytu.tuskegee.edu

\section{A B S T R A C T}

Aim: The aim was to examine the anti-proliferative effect of a Withania somnifera (WS) root extract in cell cultures and nude mouse xenografts of breast cancer cell line MDA-MB-231. Methods: WS root extract was used to treat tumor cells at concentrations up to $100 \mu \mathrm{g}$ and for nude mouse experiments, the mice received daily WS at $300 \mathrm{mg} / \mathrm{kg}$ by oral gavage for 8 weeks. Results: The WS extract reduced viability of MDA-MB-231 cells by $75 \%$ and $88 \%$ after exposure of the cells to 50 and $100 \mu \mathrm{g} / \mathrm{mL}$, respectively, compared to vehicle-treated controls. WS extract caused a dose-dependent increase in the percentage of cells in the sub-G1 phase compared to untreated controls by $6 \%$ and $10 \%$ after exposure to 25 and $50 \mu \mathrm{g} / \mathrm{mL} \mathrm{WS}$ extract, respectively. WS extract also inhibited proliferation of xenografted MDA-MB-231 cells. The WS extract caused reductions in xenograft size by $60 \%$ compared to the untreated control after 8 weeks of treatment. Six of ten mice in the control group showed tumor metastasis to the lung, whereas there was none in the mice treated with the WS extract. At the gene level, WS caused a $75 \%$ reduction in chemokine CCL2 expression $(P<0.05)$ in the xenografted tumors of the treated mice. Conclusion: WS root extract inhibited proliferation of breast cancer cells in vitro and in vivo and significantly reduced expression of the cytokine, CCL2. These results warrant further studies to assess the underlying molecular mechanism of the anti-tumor activity of the WS extract in breast cancer.

Key words: Withania somnifera extract, MDA-MB-231, breast cancer, metastasis, animal model

\section{Introduction}

Invasive breast cancer is considered one of the great challenges for clinicians to control and improve survival of patients. In 2013, an estimated 232,340 new cases of invasive breast cancer were diagnosed in women in the USA, along with other 64,640 cases of non-invasive breast cancer. $^{[1]}$ For women under 45, deadly forms of this type of breast cancer are more common in African-American women than white women, and African-American women are more likely to die of breast cancer. ${ }^{[2]}$ Despite three decades of advances in treatment of breast cancer using hormone receptor modulators, aromatase inhibitors, and surgery, ${ }^{[3-5]}$ mortality remains high due to tumor metastasis to the lymph nodes, liver, and lung. ${ }^{[6]}$ Triple-negative breast cancer (TNBC) accounts for $10-20 \%$ of diagnosed breast cancers and is more likely to affect younger African Americans, Hispanics, and/or those with BRCAl mutations. TNBCs are more aggressive, difficult to treat, and more likely

\begin{tabular}{|l|l|}
\hline \multicolumn{2}{|c|}{ Access this article online } \\
\hline Quick Response Code: & Website: \\
\hline & www.jcmtjournal.com \\
\cline { 2 - 2 } & \\
\hline
\end{tabular}

to spread and recur. ${ }^{[2]}$ TNBCs are different from other kinds of breast cancer in that they are highly metastatic and resistant to conventional therapies, such as anticancer drugs and radiation. ${ }^{[2]}$

In a search for an agent that inhibits proliferation and invasion of TNBCs, we evaluated an extract derived from an Indian herb, Withania somnifera (WS), which is a nightshade medicinal plant that contains active components for the treatment of a variety of ailments, including cancer. ${ }^{[7-10]}$ The use of WS root extract is practical since it contains the active compounds present in the plant. In TNBC cells, sub-cytotoxic concentrations of withaferin A, derived from WS, reduce various effectors of metastasis. ${ }^{[1]}$ In the present study, we assessed the effect of the WS extract on proliferation and metastasis of MDA-MB-231 cells, derived from a TNBC, in cell cultures, and in mice.

\section{Methods}

\section{Preparation of WS extract}

Roots of WS were ground to a paste, and then extracted with 5 volumes of $70 \%$ ethanol by stirring for 2 days. The alcoholic extract was filtered, and the solvent was evaporated under a vacuum. The extract was then dried to a powder and kept in a closed container until use. ${ }^{[12]}$ To avoid variations in the activity of different preparations, the sufficient extract was obtained in one batch for use throughout the experiments. 


\section{Reagents and antibodies}

WS roots were purchased from a local market in the USA and dimethyl sulfoxide (DMSO) from Sigma (St. Louis, MO, USA). Antibodies (anti-chemokine CCL2, CXCL1, CXCL2, CXCL3, PARP, and GAPDH) were from Cell Signaling (Beverly, MA, USA). Human breast cancer MDA-MB-231 cell line and a normal breast cell line, MCF10A, were obtained from ATCC (Manassas, VA, USA). The HCA-II human cytokine primer kit was obtained from Real Time Primers (Elkins Park, PA, USA).

\section{Cell culture and treatment}

Breast cancer MDA-MB-231 cells were maintained in Dulbecco's Modified Eagle's Medium (ATCC) supplemented with $10 \%$ fetal bovine serum and penicillin/streptomycin. MCF10A cells were maintained in complete MEGM (Lonza, Houston, TX, USA). All cell cultures were incubated at $37{ }^{\circ} \mathrm{C}$ with $5 \% \mathrm{CO}_{2}$ in a humidified incubator.

\section{Assessment of cell viability}

To assess the effect of the WS extract on regulation of cell viability, cells were seeded into 96-well, 6-well or $6-\mathrm{cm}$ plates at densities of $10^{3}, 10^{4}$ or $10^{5}$ cells per well, respectively. For experiments requiring longer than $48 \mathrm{~h}$, cell numbers were reduced by one half. Viability was assessed by using the 3-(4,5-dimethylthiazol-2-yl)-5(3-carboxymethoxyphenyl)-2-(4-sulfophenyl)-2H-tetrazo lium assay in 96-well plates in triplicate with CellTiter $96^{\circledR}$ AQueous One Solution cell proliferation kits from Promega (Madison, WI) according to the manufacturer's instructions. Absorbance was recorded at $490 \mathrm{~nm}$ using a Synergy HT multimode plate reader or PowerWave XS2 $\left(\right.$ BioTek $^{\circledR}$, Winooski, VT, USA) reader. DMSO was used as a control. To calculate the viability index, absorbance readings from DMSO-treated control wells were set at $100 \%$, and the relative A490 was calculated as a percentage of the control.

\section{Flow cytometry}

Cells treated with the WS extract were harvested and prepared for flow cytometry as described by Samuel et al., ${ }^{[13]}$ with some modifications. WS treated and untreated cells were harvested by trypsinization in $0.25 \%$ trypsin/ethylenediaminetetraacetic acid. Prior to trypsinization, floating or loose cells were harvested by gentle rocking of the culture dishes and transferring the culture medium containing the cells into centrifuge tubes. Trypsinized and detached cells were then combined and centrifuged. Cell pellets were suspended in $300 \mu \mathrm{L}$ of phosphate-buffered saline (PBS), fixed with $700 \mu \mathrm{L}$ of $100 \%$ ethanol with vortexing, and stored at $-20{ }^{\circ} \mathrm{C}$ overnight. The fixed cells were centrifuged and stained in fluorescence-activated cell sorting staining solution (3 $\mathrm{mg} / \mathrm{mL}$ RNase $\mathrm{A}, 0.4 \mathrm{mg} / \mathrm{mL}$ propidium iodide) in PBS without calcium or magnesium for $30 \mathrm{~min}$ at $37^{\circ} \mathrm{C}$ and then filtered through a 70- $\mu \mathrm{m}$ filter and analyzed by flow cytometry (FACScalibur ${ }^{\circledR}$ Becton Dickinson or C6 Accuri $^{\circledR}$ flow cytometer). Data were analyzed with CellQuest and CFlow software (BD).

\section{Immunocytochemistry}

Breast cancer MDA-MB-231 cells were seeded in 4-well plates and grown for $16 \mathrm{~h}$. The cells were then treated with DMSO (vehicle) or with 25 or $50 \mu \mathrm{g} / \mathrm{mL}$ of WS root extract for $18 \mathrm{~h}$. After treatment, the culture medium was removed, and the cells were fixed with $10 \%$ neutral buffered formalin. Xenograft tissues were placed in an automatic tissue processor, embedded in paraffin, sectioned at $5-\mu \mathrm{m}$ thickness, and stained with hematoxylin and eosin (HE). For immunohistochemistry, the fixed cells and tissues from xenografted tumors were stained with CCL2 antibody because this cytokine is considered to be most responsible for metastasis of breast cancer. ${ }^{[14]}$ The sections were de-paraffinized in xylene and rehydrated through a series of graded ethanol $(100 \%, 95 \%$, and $70 \%)$ and in water for $5 \mathrm{~min}$ each. The sections were then washed three times for $5 \mathrm{~min}$ each in PBS containing $0.05 \%$ Tween $80(\mathrm{pH}$ 7.4). Antigen retrieval was achieved by heating the sections in a microwave with $0.01 \mathrm{~mol} / \mathrm{L}$ sodium citrate $(\mathrm{pH}$ 6.0) solution and subsequently cooling down to room temperature. Endogenous peroxidase activity was blocked by incubating the sections for $30 \mathrm{~min}$ in $1 \%$ hydrogen peroxide in methanol. Non-specific binding was blocked by incubating the sections for $1 \mathrm{~h}$ with a normal horse serum (Vector Laboratories, Inc., Burlingame, CA, USA). The sections were then incubated with mouse anti-CCL2 (MCP-1, eBioscience, San Diego, CA, USA) overnight at $4{ }^{\circ} \mathrm{C}$. On the next day, the sections were rinsed 3 times with PBS at room temperature and then further incubated with goat anti-mouse IgG-FITC (Santa Cruz Biotechnology, Santa Cruz, CA, USA) for $1 \mathrm{~h}$ at room temperature. The fluorescence was then read using a wide-field fluorescent microscope (Olympus, Center Valley, PA, USA). Stained sections were reviewed and scored according to the intensity of staining $(0,+1,+2$ or +3$)$ and for the percentage of tumor cells staining positive for CCL2 $(0 \%, 0.1-30 \%,+1 ; 31-70 \%,+2 ;$ or $>70 \%,+3)$. The score of the intensity of immunostaining was multiplied by the score of percentage of cell staining to obtain the final staining index.

\section{$R N A$ isolation and quantitative reverse transcription-polymerase chain reaction}

Total RNA was isolated from treated and control samples with RNeasy Mini Kits (Qiagen, Valencia, CA, USA) and reversely transcribed into cDNA using Quantitect Reverse Transcriptase Kits (Qiagen) according to the manufacturer's instructions. All primers were from SABiosciences (Valencia, CA, USA); and quantitative polymerase chain reaction (qPCR) amplification was performed using $50 \mathrm{ng}$ of cDNA, $10 \mu \mathrm{L}$ of Brilliant III Ultra-Fast SYBR Green qPCR Master Mix 
(Agilent Technologies, Santa Clara, CA, USA), and $500 \mathrm{nM}$ of each primer. $\beta$-Actin was used as the internal control, and the final reactions were adjusted to a total volume of $20 \mu \mathrm{L}$ with DNase RNase-free water (Qiagen). All qPCR amplification was performed in duplicates with a Stratagene Mx 3005P system (Agilent Technologies), and the conditions were set to initial cycle of denaturation at $95{ }^{\circ} \mathrm{C}$ for $10 \mathrm{~min}, 40$ cycles of denaturation at $95{ }^{\circ} \mathrm{C}$ for $30 \mathrm{~s}$, annealing at $55{ }^{\circ} \mathrm{C}$ for $1 \mathrm{~min}$, and extension at $72{ }^{\circ} \mathrm{C}$ for $1 \mathrm{~min}$. The final segment involved generation of a dissociation curve. This comprised one cycle at $95{ }^{\circ} \mathrm{C}$ for $1 \mathrm{~min}$, followed by $55^{\circ} \mathrm{C}$ for $30 \mathrm{~s}$ and $95{ }^{\circ} \mathrm{C}$ for $30 \mathrm{~s}$. Inclusion of a dissociation curve in each qPCR run ensured specificity of the amplicon.

\section{Microarray analysis}

To determine the effect of WS extract on expression of cytokines in MDA-MB-231 cells, cells were incubated overnight with either $50 \mu \mathrm{g} / \mathrm{mL}$ WS or DMSO (vehicle) as a control. The analysis was accomplished by use of HCA-II cytokine primer library II according to the manufacturer's instructions.

\section{Experimental mice and treatments}

Athymic Nude-Foxn $1^{\text {nu }}$ mice at 6 weeks of age were obtained from Harlan Sprague-Dawley and housed in animal quarters at $22{ }^{\circ} \mathrm{C}$ with a $12 \mathrm{~h}$ light/dark cycle. Animals were given free access to water and food. These studies were approved by the Tuskegee University Institutional Animal Care and Use Committee. At 8 weeks of age, mice were injected subcutaneously with $0.2 \mathrm{~mL}$ of PBS containing $1.5 \times 10^{6}$ human breast cancer MDA-MB-231 cells into the right flanks. Twenty mice that developed tumor sizes of 50-200 $\mathrm{mm}^{3}$ were divided into two equal groups. The control group received $0.2 \mathrm{~mL}$ of $5 \%$ DMSO orally by gavage, and the treated group received $300 \mathrm{mg} / \mathrm{kg} /$ day WS root extract dissolved in $5 \%$ DMSO orally by gavage daily for 5 days a week for 8 weeks. Tumor sizes were checked weekly in each group. Tumor dimensions in $\mathrm{mm}$ (length and width) were measured with vernier calipers and calculated for each tumor by using the following equation: tumor volume $=1 / 2\left(\right.$ length $\times$ width $\left.^{2}\right)$. At the end of the 8 th week, mice were euthanized with $\mathrm{CO}_{2}$. Tumors and lung tissues were collected and fixed with $10 \%$ formalin for histopathological and immunochemistry analysis.

\section{Evaluation of lung metastasis}

Two pathologists histopathologically evaluated lung metastases in untreated and treated groups after staining of sections with $\mathrm{HE}$, and the results were reported independently. The number of metastatic foci was counted in each stained tissue section.

\section{Statistical analyses}

Student's $t$-test was used to assess differences between values for the treated and control groups. One-way analysis of variance was used with Dunnett's test.

\section{Results}

WS extract caused a dose-dependent reduction of viability of breast cancer MDA-MB-231 cells by $75 \%$ and $88 \%$ after treatment with 50 or $100 \mu \mathrm{g} / \mathrm{mL}$ WS extract, respectively, compared to vehicle-treated controls [Figure 1], but WS treatment did not affect the viability of non-cancerous epithelial mammary cells, MCF10A [Figure 2]. Moreover, compared to untreated controls, WS extract caused a concentration-dependent increase in the sub-G1 phase of the cell population, by $6 \%$ and $10 \%$ after exposure to $25 \mu \mathrm{g} / \mathrm{mL}$ and $50 \mu \mathrm{g} / \mathrm{mL}$, respectively [Figure 3].

Furthermore, WS extract inhibited proliferation of xenografted MDA-MB-231 cells, reducing the size of xenografted tumors by $60 \%$ compared to the untreated control after 8 weeks of treatment $(P<0.05)$ [Figure 4]. In addition, after euthanasia, six of ten mice in the control group showed tumor metastasis to the lung, whereas none of the mice in WS-treated group developed metastasized tumor lesions in the lung [Figure 5]. This finding motivated us to explore the underlying molecular mechanism by which the WS extract inhibited tumor metastases to the lung.

Microarray analysis of gene expression of cytokines was then performed. WS suppressed expression of CCL2, CXCL1, CXCL2, CXCL3, IL1B, TGFB3, and BMP4 mRNA [Figure 6]. These inhibitory effects were confirmed by quantitative reverse transcriptionpolymerase chain reaction analysis [Figure 7]. WS caused a $75 \%$ reduction in CCL2 expression $(P<0.05)$ in the xenografted tumors of treated mice [Figure 8].

\section{Discussion}

The current study assessed the effect of an alcoholic extract of WS roots on proliferation and metastasis of

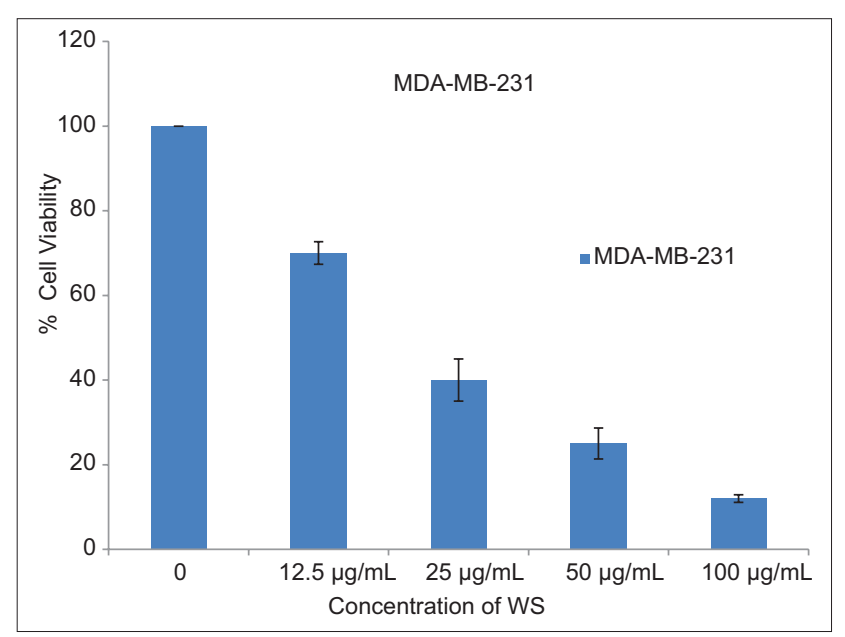

Figure 1: Effect of WS on viability of breast cancer MDA-MB-231 cells. The bars represent the mean \pm standard deviation of six 24-h treatments for the vehicle and different concentrations of WS. The results are statistically significant $(P<0.05)$ compared to the DMSO-treated (control) cells as determined by one-way ANOVA with Dunnett's test. WS: Withania somnifera; ANOVA: Analysis of variance; DMSO: Dimethyl sulfoxide 
breast cancer MDA-MB-231 cells in vitro and in nude mice, respectively. WS roots have been used in ayurvedic medicine for their anti-inflammatory, analgesic, anticancer, and anti-stress properties. ${ }^{[7,8]}$ These diverse effects are attributed to the presence of active steroidal compounds that are called withanolides. ${ }^{[15]}$ Our current data showed that the WS extract inhibited proliferation and metastasis of MDA-MB-231 cells in vitro and in nude mice. This inhibition was greater than that caused by withaferin A. ${ }^{[16]}$ The difference in inhibition may be attributed to the fact that the whole extract contains active ingredients that have a synergistic effect against breast cancer cells. ${ }^{[7,17]}$ Since MDA-MB-231 cells are "triple-negative" form estrogen-independent tumors in vivo, the anti-proliferative effect of WS is apparently

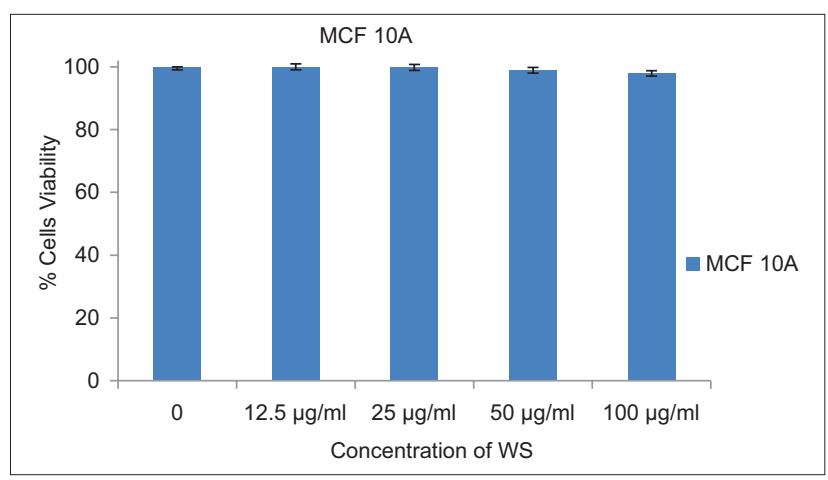

Figure 2: Effect of WS on the viability of non-cancerous epithelial mammary cells, MCF10A.The bars represent the mean \pm standard deviation of six $72-h$ treatments for the vehicle and different concentrations of WS. As determined by one-way ANOVA, results of treated cells are not statistically significant compared to the DMSO-treated (control) cells. WS: Withania somnifera; ANOVA: Analysis of variance; DMSO: Dimethyl sulfoxide estrogen-independent. The WS extract caused increases in the percentage of MDA-MB-231 cells in the sub-G1 phase, indicating that WS causes apoptosis. Withaferin A, one of the active compounds of WS, causes $\mathrm{G}(2) / \mathrm{M}$ cell cycle arrest, associated with modulation of cyclin B1, p34(cdc2), and PCNA levels, decreases the levels of STAT3 and its phosphorylation at $\operatorname{Tyr}(705)$ and $\operatorname{Ser}(727)$, and alters expression levels of p53-mediated apoptotic markers-Bcl2, Bax, caspase-3, and cleaved PARP. ${ }^{[18]}$

Results of our current mouse experiments are consistent with in vitro data. The WS extract, administered orally, inhibited formation and growth of MDA-MB-231 cell xenografts in nude mice, indicating that the active ingredients of the WS extract are bioavailable after oral administration. ${ }^{[19]}$ Six mice of the untreated group developed tumor metastasis to the lung, whereas none of the treated mice showed such tumor metastases. This effect may be attributed to inhibition of CCL2 in xenografted tumors after treatment with WS root extract. These results are consistent with a previous study ${ }^{[20]}$ concerning the inhibition of CCL2 in animals. Inhibition of CCL2/CCR2 signaling by anti-CCL2 antibodies blocks recruitment of inflammatory monocytes, inhibits metastasis, and prolongs the survival of tumor-bearing mice. Depletion of tumor cell-derived CCL2 also inhibits metastatic seeding. Moreover, CCL2 mediates development of cancer stem cell (CSC) phenotypes. Promotion of CSC is relevant since these cells, through self-renewal, maintain heterogeneity and give rise to metastasis of breast cancer. $^{[21]}$

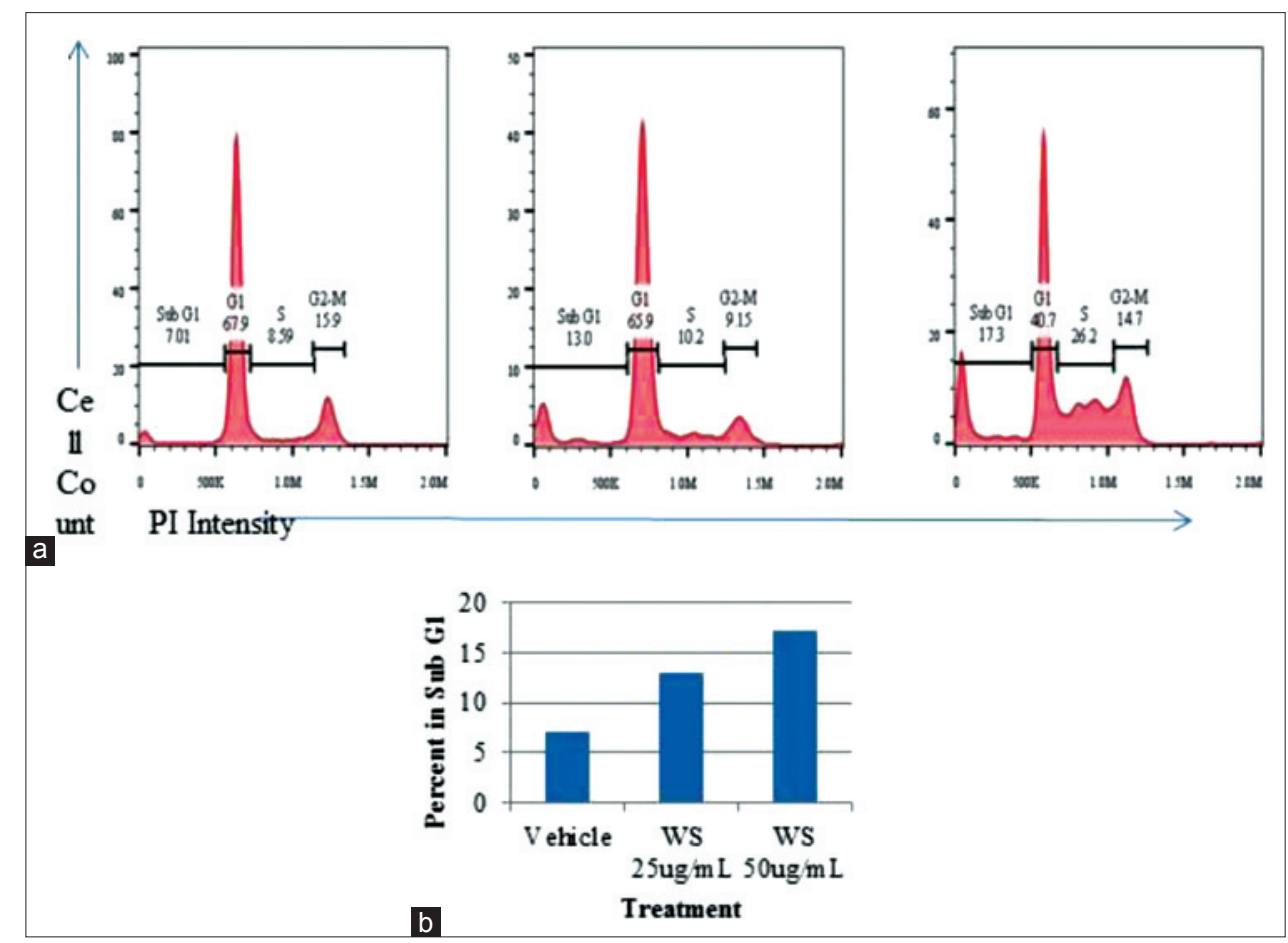

Figure 3: Effect of different concentrations of WS on the cell cycle of MDA-MB231 breast cancer cells. (a) Cell cycle histograms by treatment (vehicle, WS $25 \mu \mathrm{g} / \mathrm{mL}$ and WS $50 \mu \mathrm{g} / \mathrm{mL}$ ). Range gates show cell percentage in each cell cycle stage; (b) percentage of cells in cell cycle arrest by treatment. WS: Withania somnifera 


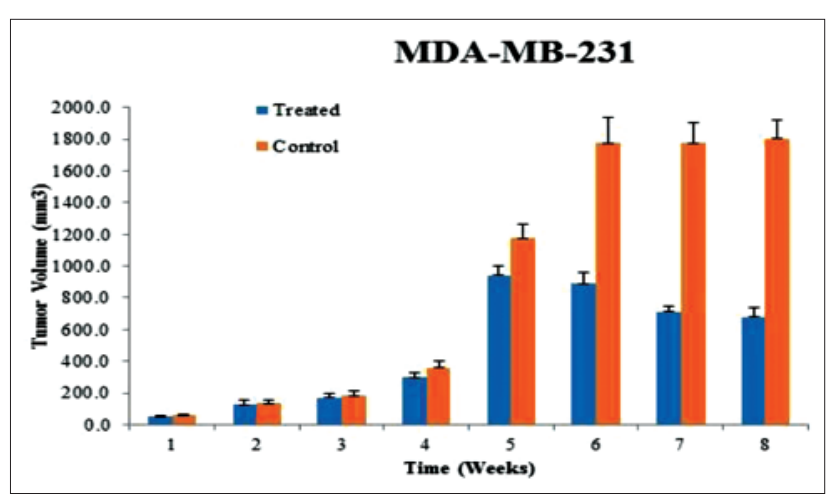

Figure 4: Effect of WS on suppression of growth of xenografted MDA-MB-231 cells in nude mice. The bars represent the means \pm standard deviations of tumor size $\left(\mathrm{mm}^{3}\right)(n=10)$. The highest reduction $(60 \%)$ relative to the untreated control was shown after 8 weeks of WS treatment $(P<0.05)$. Student's $t$-test was used to assess significant differences between treated groups and the untreated control group. WS: Withania somnifera

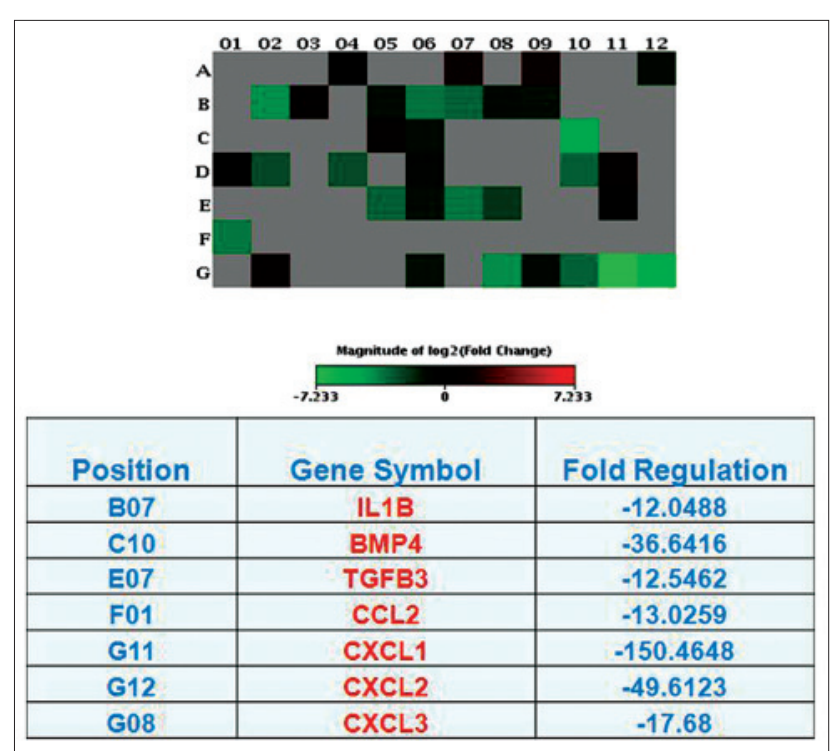

Figure 6: Effect of WS on inhibition of cytokine/chemokine expression. WS: Withania somnifera

Our current data are consistent with those reported by others. ${ }^{[17]}$ A root extract of WS showed dose-dependent inhibition of tumor growth and metastatic lung nodule formation with the minimal toxicity to mice. ${ }^{[17]}$ The extract apparently inhibited cancer metastasis through inhibition of the epithelial-mesenchymal transition (EMT). Furthermore, withaferin A treatment of MCF-10A cells inhibited EMT and in mice, reduced mammary cancer growth, effects of which were associated with reduced vimentin expression. ${ }^{[22]}$ In the present study, the oral dose of WS extract used to inhibit tumor metastasis to the lungs was $300 \mathrm{mg} / \mathrm{kg} / \mathrm{day}$ body weight. This dose was extrapolated from the cell culture experiments regarding the effect of WS extract on MDA-MB-230 cells. This dose was selected based on a pilot study involving a range of doses to estimate

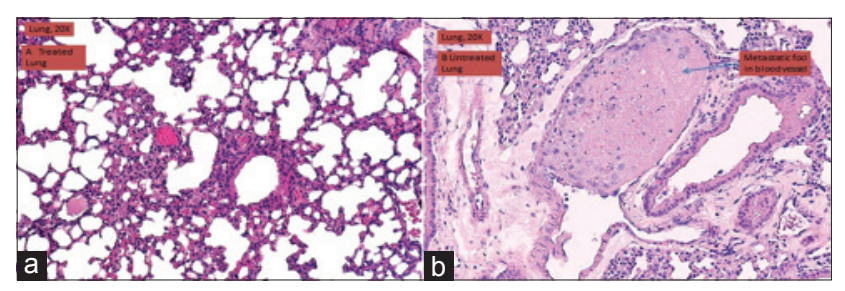

Figure 5: Effect of WS treatment on inhibition of lung metastasis in nude mice. HE staining of lung tissue sections after treatment with or without WS for 8 weeks $(\times 20)$. (a) WS treated mouse lungs showed no tumor metastasis $(n=10)$; (b) six of ten mice showed tumor metastasis to the lungs, with a total of 12 metastatic foci in the blood vessels and the parenchyma of the lungs in control mice. WS: Withania somnifera

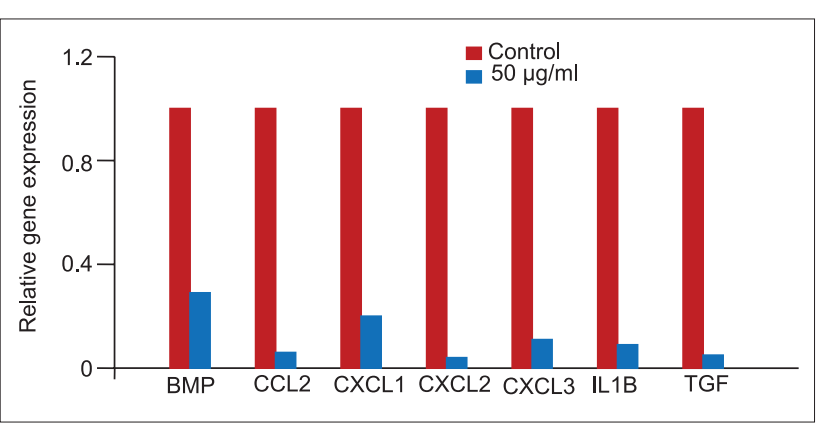

Figure 7: Effect of WS treatment on the regulation of cytokine expression. Quantitative reverse transcription-polymerase chain reaction was used to measure cytokine expression in cells treated or not treated with $50 \mu \mathrm{g} / \mathrm{mL}$ WS. WS: Withania somnifera

the optimal dose. In addition, the in vitro cytotoxic concentration, ranging between 50 and $100 \mu \mathrm{g} / \mathrm{mL}$, gave us an idea about the dose. In a previous study, WS root extract inhibited lung metastasis of xenografted MDA-MB-231 cells at a dose of $8 \mathrm{mg} / \mathrm{kg}$ body weight, administered 3 times a week for 4 weeks. ${ }^{[19]}$ This dose is 37.5 times less than the dose used in our current study. There is no obvious explanation for the difference in the two doses. Differences in the source of roots, age of roots, and extraction yield may contribute to different dose-responses when using crude plant extracts. However, the WS extract, at a dose of $150 \mathrm{mg} / \mathrm{kg} /$ day for 155 days, caused a $23 \%$ reduction in development of mammary tumors in rats administered the carcinogen, methylnitrosourea. ${ }^{[23]}$

In transgenic (MMTV/Neu) mice that received a diet containing the extract $(750 \mathrm{mg} / \mathrm{kg}$ of diet) for 10 months, mice in the treated group $(n=35)$ had an average of 1.66 mammary tumors, and mice in the control group $(n=33)$ had 2.48 , a reduction of $33 \%$. Moreover, in treated mice, WS caused a $50 \%$ reduction in the expression of CCL2. ${ }^{[24]}$

WS caused in vitro and in vivo inhibition of breast cancer MDA-MB-231 cells and caused a significant reduction in expression of the cytokine, CCL2, a marker of the metastasis of breast cancer to other organs. These results warrant further studies to assess the underlying 


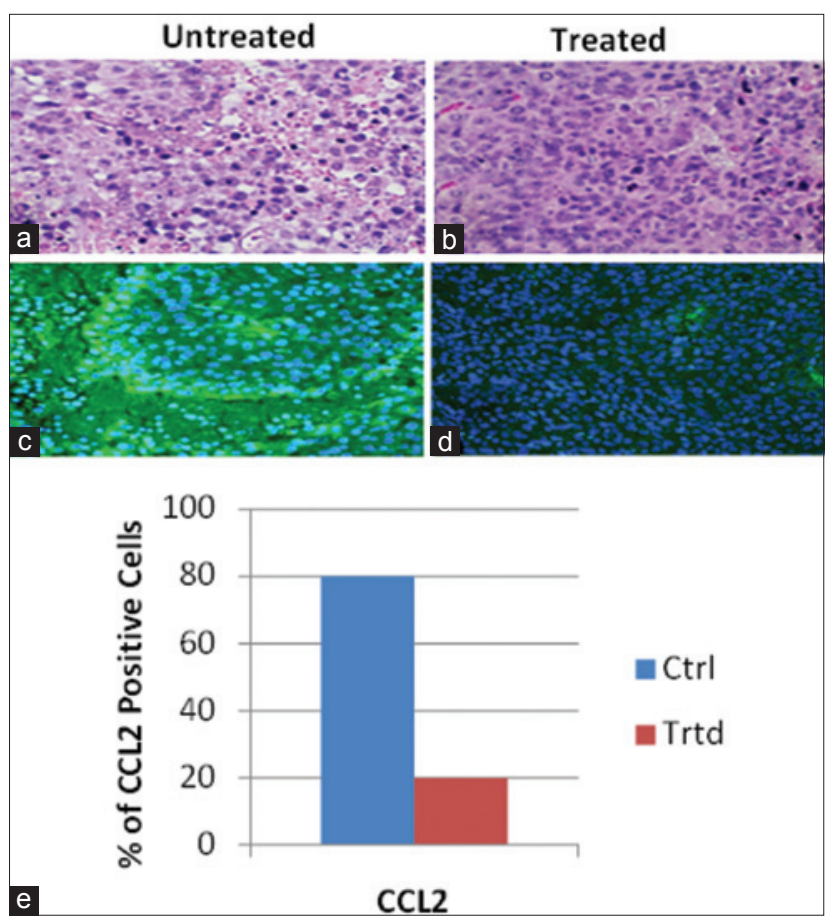

Figure 8: Effect of WS on expression of CCL2 in MDA-MB-231 xenografted tumors. ( $a$ and $b, \times 20)$ Hematoxylin and eosin sections of untreated and WS treated tumors, respectively; (c and d, $\times 20$ ) immunohistochemical staining of CCL2 in untreated and WS treated tumors; (e) summarized data. There was a significant reduction $(P<0.05)$ in CCL2 expression in WS-treated tumors compared to untreated tumors as determined by Student's $t$-test. WS: Withania somnifera; CCL2: Chemokine (C-C motif) ligand 2

molecular mechanism of WS extract antitumor activity in the breast cancer metastasis.

\section{Acknowledgments}

This project was supported by NIH Grant U54 CA 118948.

\section{References}

1. Cancer Facts and Figures. American Cancer Society; 2014. Available from: http://www.cancer.org/research/cancerfactsstatistics/ cancerfactsfigures 2014/. [Last accessed on 2015 Mar 14].

2. Triple Negative Breast Cancer. Available from: http:// www.nationalbreastcancer.org/triple-negative-breast-cancer. [Last accessed on 2015 Mar 14].

3. Fisher B, Costantino JP, Wickerham DL, Redmond CK, Kavanah M, Cronin WM, Vogel V, Robidoux A, Dimitrov N, Atkins J, Daly M, Wieand S, Tan-Chiu E, Ford L, Wolmark N. Tamoxifen for prevention of breast cancer: report of the National Surgical Adjuvant Breast and Bowel Project P-1 Study. J Natl Cancer Inst 1998;90:1371-88.

4. Cauley JA, Norton L, Lippman ME, Eckert S, Krueger KA, Purdie DW, Farrerons J, Karasik A, Mellstrom D, Ng KW, Stepan JJ, Powles TJ, Morrow M, Costa A, Silfen SL, Walls EL, Schmitt H, Muchmore DB, Jordan VC, Ste-Marie LG. Continued breast cancer risk reduction in postmenopausal women treated with raloxifene: 4-year results from the MORE trial. Multiple outcomes of raloxifene evaluation. Breast Cancer Res Treat 2001;65:125-34.

5. Goss PE, Ingle JN, Alés-Martínez JE, Cheung AM, Chlebowski RT, Wactawski-Wende J, McTiernan A, Robbins J, Johnson KC, Martin LW, Winquist E, Sarto GE, Garber JE, Fabian CJ, Pujol P, Maunsell E, Farmer P, Gelmon KA,
Tu D, Richardson H; NCIC CTG MAP. 3 Study Investigators. Exemestane for breast-cancer prevention in postmenopausal women. N Engl J Med 2011;364:2381-91.

6. Kennecke H, Yerushalmi R, Woods R, Cheang MC, Voduc D, Speers CH, Nielsen TO, Gelmon K. Metastatic behavior of breast cancer subtypes. J Clin Oncol 2010;28:3271-7.

7. Mishra LC, Singh BB, Dagenais S. Scientific basis for the therapeutic use of Withania somnifera (ashwagandha): a review. Altern Med Rev 2000;5:334-46.

8. Winters M. Ancient medicine, modern use: Withania somnifera and its potential role in integrative oncology. Altern Med Rev 2006;11:269-77.

9. Newman DJ, Cragg GM. Natural products as sources of new drugs over the last 25 years. J Nat Prod 2007;70:461-77.

10. Jayaprakasam B, Zhang Y, Seeram NP, Nair MG. Growth inhibition of human tumor cell lines by withanolides from Withania somnifera leaves. Life Sci 2003;74:125-32.

11. Szarc vel Szic K, Op de Beeck K, Ratman D, Wouters A, Beck IM, Declerck K, Heyninck K, Fransen E, Bracke M, De Bosscher K, Lardon F, Van Camp G, Vanden Berghe W. Pharmacological levels of Withaferin A (Withania somnifera) trigger clinically relevant anticancer effects specific to triple negative breast cancer cells. PLoS One 2014;9:e87850.

12. Senthilnathan P, Padmavathi R, Magesh V, Sakthisekaran D. Modulation of TCA cycle enzymes and electron transport chain systems in experimental lung cancer. Life Sci 2006;78:1010-4.

13. Samuel T, Okada K, Hyer M, Welsh K, Zapata JM, Reed JC. cIAP1 Localizes to the nuclear compartment and modulates the cell cycle. Cancer Res 2005;65:210-8.

14. Li M, Knight DA, Snyder LA, Smyth MJ, Stewart TJ. A role for CCL2 in both tumor progression and immunosurveillance. Oncoimmunology 2013;2:e25474.

15. Namdeo AG, Sharma A, Yadav KN, Gawande R, Mahadik KR, Lopez-Gresa MP, Kim HK, Choi YH, Verpoorte R. Metabolic characterization of Withania somnifera from different regions of India using NMR spectroscopy. Planta Med 2011;77:1958-64.

16. Stan SD, Hahm ER, Warin R, Singh SV. Withaferin A causes FOXO3a-and Bim-dependent apoptosis and inhibits growth of human breast cancer cells in vivo. Cancer Res 2008;68:7661-9.

17. Subbaraju GV, Vanisree M, Rao CV, Sivaramakrishna C, Sridhar P, Jayaprakasam B, Nair MG. Ashwagandhanolide, a bioactive dimeric thiowithanolide isolated from the roots of Withania somnifera. J Nat Prod 2006;69:1790-2.

18. Munagala R, Kausar H, Munjal C, Gupta RC. Withaferin A induces p53-dependent apoptosis by repression of HPV oncogenes and upregulation of tumor suppressor proteins in human cervical cancer cells. Carcinogenesis 2011;32:1697-705.

19. Yang Z, Garcia A, Xu S, Powell DR, Vertino PM, Singh S, Marcus AI. Withania somnifera root extract inhibits mammary cancer metastasis and epithelial to mesenchymal transition. PLoS One 2013;8:e75069.

20. Qian BZ, Li J, Zhang H, Kitamura T, Zhang J, Campion LR, Kaiser EA, Snyder LA, Pollard JW. CCL2 recruits inflammatory monocytes to facilitate breast-tumour metastasis. Nature 2011;475:222-5.

21. Palacios-Arreola MI, Nava-Castro KE, Castro JI, Garcia-Zepeda E, Carrero JC, Morales-Montor J. The role of chemokines in breast cancer pathology and its possible use as therapeutic targets. J Immunol Res 2014;2014:849720.

22. Lee J, Hahm ER, Marcus AI, Singh SV. Withaferin A inhibits experimental epithelial-mesenchymal transition in MCF-10A cells and suppresses vimentin protein level in vivo in breast tumors. Mol Carcinog 2013;54:417-29. 
23. Khazal KF, Samuel T, Hill DL, Grubbs CJ. Effect of an extract of Withania somnifera root on estrogen receptor-positive mammary carcinomas. Anticancer Res 2013;33:1519-23.

24. Khazal KF, Hill DL, Grubbs CJ. Effect of Withania somnifera root extract on spontaneous estrogen receptor-negative mammary cancer in MMTV/Neu mice. Anticancer Res 2014;34:6327-32.
How to cite this article: Khazal KF, Hill DL. Withania somnifera extract reduces the invasiveness of MDA-MB-231 breast cancer and inhibits cytokines associated with metastasis. J Cancer Metastasis Treat 2015;1:94-100.

Received: 23-01-2015; Accepted: 15-04-2015.

Source of Support: Nil, Conflict of Interest: None declared. 